\title{
Composition and luminescence of AllnGaN layers grown by plasma-assisted molecular beam epitaxy
}

\author{
K. Bejtka, ${ }^{1}$ P. R. Edwards, ${ }^{1}$ R. W. Martin, ${ }^{1, a)}$ S. Fernández-Garrido, ${ }^{2}$ and E. Calleja ${ }^{2}$ \\ ${ }^{1}$ Department of Physics, SUPA, Strathclyde University, Glasgow G4 ONG, United Kingdom \\ ${ }^{2}$ ISOM and Departamento de Ingeniería Electrónica, ETSI Telecomunicacion, Universidad Politécnica \\ de Madrid, 28040 Madrid, Spain
}

(Received 4 March 2008; accepted 20 August 2008; published online 15 October 2008)

\begin{abstract}
A study of AlInGaN epilayers, grown by plasma-assisted molecular beam epitaxy, was performed using spatially resolved $\mathrm{x}$-ray microanalysis and luminescence spectroscopy in order to investigate competition between the incorporation of $\mathrm{In}, \mathrm{Al}$, and $\mathrm{Ga}$ as a function of the growth temperature in the $565-660{ }^{\circ} \mathrm{C}$ range and the nominal AlN mole fraction. The samples studied have AlN and InN mole fractions in the ranges of $4 \%-30 \%$ and $0 \%-16 \%$, respectively. Composition measurements show the effect of decreasing temperature to be an increase in the incorporation of $\mathrm{InN}$, accompanied by a small but discernible decrease in the ratio of $\mathrm{GaN}$ to AlN mole fractions. The incorporation of In is also shown to be significantly increased by decreasing the $\mathrm{Al}$ mole fraction. Optical emission peaks, observed by cathodoluminescence mapping and by photoluminescence, provide further information on the epilayer compositions as a function of substrate temperature, and the dependencies of peak energy and linewidth are plotted. (C) 2008 American Institute of Physics.
\end{abstract}

[DOI: $10.1063 / 1.2993549]$

\section{INTRODUCTION}

The quaternary alloy AlInGaN offers significant potential for the fabrication of advanced III-N heterostructures and improvement of the quantum efficiency of light emitters, ${ }^{1,2}$ particularly in the UV region. The quaternary material enables the separate control of strain and band gap, increasing the flexibility of sample design and functionality. AlInGaN lattice matched to $\mathrm{GaN}$ is of particular interest since it does not incorporate the strain and associated piezoelectric polarization in heterostructures grown along the $c$-axis. Assuming the validity of Vegard's law for the $a$-lattice parameter in $\mathrm{AlInGaN}$, an $\mathrm{Al} / \mathrm{In}$ ratio of 4.7 gives lattice match to $\mathrm{GaN}$.

Plasma-assisted molecular beam epitaxy (PA-MBE) offers several advantages over other epitaxial growth techniques including in situ control of the growth by high energy electron diffraction (RHEED), low impurity incorporation, $p$-type doping without an activation process, and the realization of atomically sharp interfaces. However the growth of AlInGaN layers over a wide compositional range is difficult due to the very different properties and optimum growth conditions of the constituent binaries. ${ }^{3-8}$ The growth temperature is the most critical parameter to achieve high quality AlIn$\mathrm{GaN}$ layers, since a balance is required between the high temperatures suited for $\mathrm{Al}-$ and $\mathrm{Ga}$-containing layers and the low temperatures needed for efficient In incorporation. ${ }^{3,5,8}$ The strong dependence of In incorporation with substrate temperature may lead to compositional nonuniformities due to temperature gradients along the wafer during growth. In addition, for a given substrate temperature In incorporation has been reported to be also limited by the AlN mole fraction. ${ }^{4,5}$ However the manner in which the In incorporation reduces with the AlN mole fraction, the underlying

\footnotetext{
${ }^{a)}$ Electronic mail: r.w.martin@strath.ac.uk.
}

mechanisms and its dependence with the specific growth conditions are still under debate.

This paper describes the growth by PA-MBE of a range of $\mathrm{Al}_{x} \mathrm{In}_{y} \mathrm{Ga}_{1-x-y} \mathrm{~N}$ epilayers $(0.05<x<0.3,0<y<0.16)$ and their characterization by wavelength dispersive $\mathrm{x}$-ray (WDX) analysis integrated with room temperature (RT) cathodoluminescence (CL) spectroscopy using an electron probe microanalyzer (EPMA). The EPMA is equipped with three WDX spectrometers and an optical microscope coaxial with the electron microscope is used to collect the luminescence. This platform is ideal for simultaneous WDX and CL hyperspectral imagings, providing mapped information on both composition and luminescence on a submicron scale. ${ }^{9}$ For the WDX analysis both AlN and Al metal standards were used to check the quantification of the AlN mole fraction in the layers. Standards of GaN and InP were used to quantify $\mathrm{Ga}, \mathrm{N}$, and In. In our experience WDX provides composition data of similar accuracy to that from Rutherford backscattering spectrometry (RBS). ${ }^{10,11}$ Advantages of WDX over RBS include the higher lateral spatial resolution (down to $100 \mathrm{~nm}$ ) and the possibility of simultaneous CL spectroscopy, while RBS has much better depth resolution. These methods have some advantages compared to measurement of AlInGaN composition using standard x-ray diffraction, which can be complicated by the lack of a unique solution for the quaternary system. The mapping facility provides information on variations in composition arising from the temperature variations across the substrate and on correlations between the compositional data and the light emitting properties of the layers. Low temperature $(15 \mathrm{~K})$ photoluminescence spectra were also measured, using low power $(5 \mathrm{~mW}) \mathrm{HeCd}$ laser excitation at $325 \mathrm{~nm}$.

Wurtzite AlInGaN epilayers $(\approx 300 \mathrm{~nm}$ thick $)$ were grown on (0001) GaN templates grown on $c$-plane sapphire 


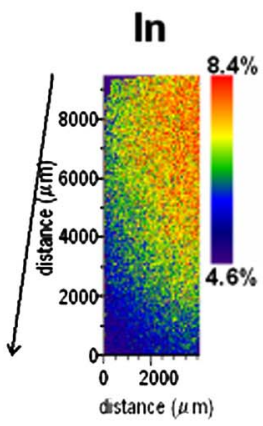

a)

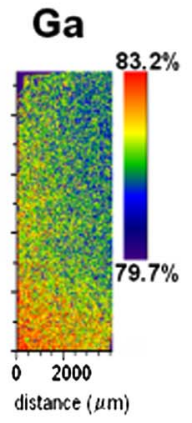

b)

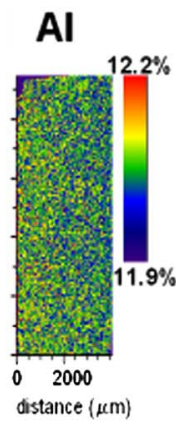

c)

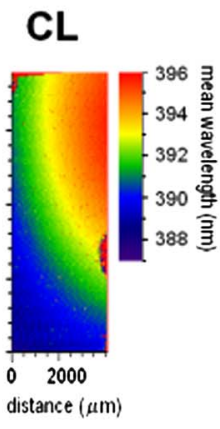

d)

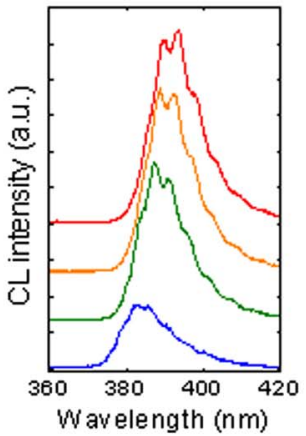

e)

FIG. 1. (Color online) [(a)-(c)] Large area composition and (d) CL maps of AlInGaN sample grown at $595{ }^{\circ} \mathrm{C}$; (e) CL spectra extracted from the CL map, corresponding to four different points.

(Lumilog), by PA-MBE in a Riber Compact 21 system equipped with an Addon rf-plasma $\mathrm{N}$ source and Knudsen cells for $\mathrm{Al}, \mathrm{Ga}$, and $\mathrm{In}$. The growth temperatures were measured in the center of the samples using an optical pyrometer. Prior to the AlInGaN growth, a $100 \mathrm{~nm}$ thick GaN buffer layer was grown at $730^{\circ} \mathrm{C}$ to obtain a smooth and flat surface. To ensure a two-dimensional growth mode and to avoid the formation of metal droplets on the surface all samples were grown within the intermediate metal-rich growth regime using a III/V flux ratio close to one. ${ }^{6}$ Two different series of AlInGaN samples were grown. In the first series (A), the substrate temperature was varied between 565 and $660{ }^{\circ} \mathrm{C}$, with all the metal fluxes $\left(\Phi_{\mathrm{Ga}}, \Phi_{\mathrm{Al}}\right.$, and $\left.\Phi_{\mathrm{In}}\right)$ and the amount of active $\mathrm{N}\left(\Phi_{\mathrm{N}}\right)$ held constant. The Al flux was $\sim 10 \%$ of $\Phi_{\mathrm{N}}$ and the sum of the Ga and Al fluxes was kept sufficiently below $\Phi_{\mathrm{N}}$, specifically $\left(\Phi_{\mathrm{Ga}}+\Phi_{\mathrm{Al}}\right) / \Phi_{\mathrm{N}} \approx 75 \%$, in order to enable the incorporation of In without droplet formation. For the second series (B), the nominal AlN mole fraction was varied between $5 \%$ and $20 \%$ (in steps of $5 \%$ ) keeping both the substrate temperature $\left(610^{\circ} \mathrm{C}\right)$ and the nominal III/V ratio constant. In this case the Ga flux was changed to compensate for changes in the Al flux, keeping $\left(\Phi_{\mathrm{Ga}}+\Phi_{\mathrm{Al}}\right) / \Phi_{\mathrm{N}} \approx 70 \%$. For both series the active nitrogen flux, expressed in equivalent $(0001) \mathrm{GaN}$ growth rate units, ${ }^{12}$ was $\Phi_{\mathrm{N}}=0.5 \mathrm{ML} / \mathrm{s}$ as determined by cross section electron microscopy of thick $\mathrm{GaN}$ layers grown under N-limited conditions at low temperature $\left(650^{\circ} \mathrm{C}\right)$. For all samples, a streaky RHEED pattern was observed during growth and no droplets were detected by optical microscopy in the grown layers.

The rotation center during the growth was in the center of the samples, each one-quarter of a 2 in. wafer. Due to edge effects, there was a small temperature gradient across the samples during growth with higher temperature close to the edges. WDX and CL measurements were performed on two pieces from each wafer (one from the center and one from the edge), each with a length of $8-12 \mathrm{~mm}$, in order to understand the effect of substrate temperature on alloy composition.

The EPMA measurements were performed with an electron beam energy of $6 \mathrm{keV}$, in order to ensure that the excitation volume was confined within the AlInGaN epilayer. RBS measurements ${ }^{13}$ show the quaternary layer thickness to range from 320 to $390 \mathrm{~nm}$ for series A (and 230-255 $\mathrm{nm}$ for samples similar to series B), increasing approximately linearly with the amount of incorporated $\mathrm{InN}$ as discussed below. At $6 \mathrm{keV}$ the depth within which $90 \%$ of the electron beam energy is deposited extends to $180 \mathrm{~nm}$ in the least dense samples, well within the minimum AlInGaN thickness. The electron beam current used was $40 \mathrm{nA}$, enabling reasonable signal-noise to be achieved within short measurement times. The resulting reduction in spatial resolution is not important in this "large-area" application.

\section{RESULTS}

WDX compositional data and simultaneously measured CL spectra were mapped. All samples showed similar variations in elemental composition and in CL peak emission energy due to temperature variations along the substrate during growth. Figure 1 presents the results from the center piece of the sample from series A grown at $595{ }^{\circ} \mathrm{C}$. Figures 1(a)-1(c) show the elemental maps from WDX measurement, acquired over an area of $4 \times 9.2 \mathrm{~mm}^{2}$, with a step size of $50 \mu \mathrm{m}$ used for the scanning of the sample stage. The arrow in Fig. 1 indicates the direction of increasing temperature across the sample during growth. The AlN mole fraction shows little variation with position, and remains close to a value of $12 \%$, while the InN mole fraction shows a steady increase from $4.6 \%$ to $8.4 \%$ with decreasing temperature along the length of the sample. At the same time as this near doubling of the InN fraction, a smaller fractional variation is observed in the $\mathrm{GaN}$ fraction, which decreases from $83.2 \%$ to $79.7 \%$.

Simultaneously with the compositional measurement each sample was mapped by CL at RT, collecting a full 1024point spectrum at each pixel. The resulting three-dimensional CL data can be visualized using a number of twodimensional maps. ${ }^{14} \mathrm{~A}$ representative map is presented in Fig. 1(d), plotting the CL peak centroid as a function of position for series A sample grown at $595^{\circ} \mathrm{C}$. Figure 1(e) shows examples of the RT CL spectra extracted from the map. The peak originates from AlInGaN and, as can be seen in the full map, its center shifts across the wafer from 387 to $396 \mathrm{~nm}$. This shift is associated with the composition variations across the wafer, resulting from the gradient in substrate temperature. 
a)

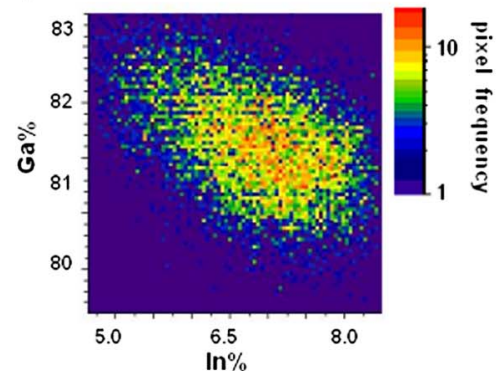

b)

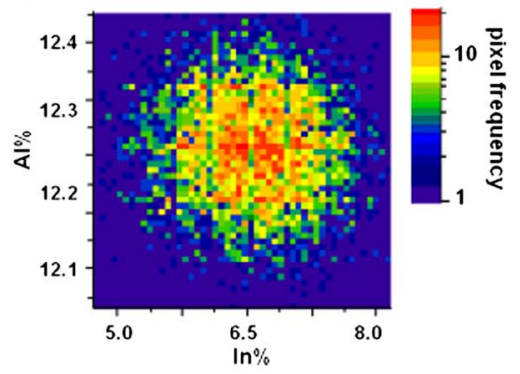

c)

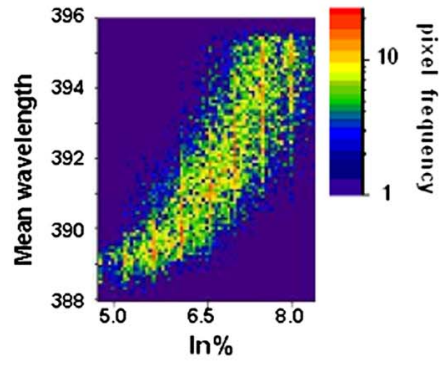

FIG. 2. (Color online) Two dimensional histograms showing correlation between (a) GaN and InN mole fraction, (b) AlN and InN mole fraction, and (c) CL luminescence wavelength and $\mathrm{InN}$ mole fraction. The frequency information is shown using a logarithmic scale.

The possibility of correlation between the indium and gallium or aluminum content can be examined statistically, as demonstrated in Figs. 2(a) and 2(b). All data points from the maps shown in Figs. 1(a)-1(c) are used to generate the two-dimensional histograms and the frequency information plotted using a logarithmic color scale. The stretching of the Ga versus In data demonstrates a degree of anticorrelation. As the InN mole fraction increases the GaN mole fraction shows an overall decrease. The symmetric plot for Al versus In, shown in (b), might be taken as an indication that these compositions are uncorrelated. However, generation of correlation plots using simulated $\mathrm{Al}$ versus In data with various levels of random noise show that, for uncertainty distributions similar to those in our measured data sets, the scatter is sufficient to mask any correlation. A correlation can, however, be demonstrated using a histogram generated from the data for mean wavelength [Fig. 1(d)] and In content [Fig. 2(c)]. This demonstrates the general tendency of the mean $\lambda$ to shift toward higher wavelength with increasing $\mathrm{InN}$ fraction. Similar correlation plots were observed for all the samples studied. The degree of variation of the incorporated elements depends on the growth temperature.

Table I summarizes the composition of the layers measured by WDX close to the center and near the edge. Quite large variations between those points are observed. The measured totals were all within 2 at. $\%$ of 100 at.\% and the data shown in the table have been normalized to 100 at. \%, in the standard way. The fractional uncertainty in the measurement is estimated to be \pm 0.01 . The growth rates determined by RBS (Ref. 13) on different "near-center" pieces of the samples in series A are also shown in Table I with uncertainties of $\pm 0.011 \mathrm{ML} / \mathrm{s}$.

In series $\mathrm{A}$ the rate of In incorporation decreases rapidly with the growth temperature, decreasing from above $15 \%$ at $565{ }^{\circ} \mathrm{C}$ to become lower than $1 \%$ at $625{ }^{\circ} \mathrm{C}$. This is driven by two factors favored by higher temperature: increased dissociation of In-N bonds and partial re-evaporation of the impinging In flux. ${ }^{3}$ The absolute variation of $\mathrm{InN}$ mole fraction along those samples grown at higher temperatures is not so large but is better expressed as a fractional variation as given in the table. This fractional variation increases dramatically for higher growth temperatures.

Since throughout the range of growth temperatures used the desorption rate of $\mathrm{Al}$ is completely negligible ${ }^{8}$ and metal was not accumulated on the growing surface (such as in the form of droplets), all impinging $\mathrm{Al}$ atoms should be incorporated into the layer. The Ga desorption rate (in vacuum) has been reported to be approximately $0.02 \mathrm{ML} / \mathrm{s}$ at $630{ }^{\circ} \mathrm{C}$ and as low as $0.005 \mathrm{ML} / \mathrm{s}$ at $600{ }^{\circ} \mathrm{C}$. ${ }^{12}$ These values are almost negligible compared to the quaternary growth rate of $\sim 0.35 \mathrm{ML} / \mathrm{s}$, especially when taking into account that the active nitrogen present during growth strongly reduces the

TABLE I. Normalized composition data for the AlInGaN epilayers measured in the center and edge by WDX.

\begin{tabular}{|c|c|c|c|c|c|c|c|c|c|}
\hline & $\begin{array}{c}T_{\text {growth }} \\
\left({ }^{\circ} \mathrm{C}\right)\end{array}$ & $\begin{array}{l}\text { InN } \\
(\%)\end{array}$ & $\begin{array}{l}\text { GaN } \\
(\%)\end{array}$ & $\begin{array}{l}\text { AIN } \\
(\%)\end{array}$ & $\begin{array}{l}\operatorname{InN} \\
(\%)\end{array}$ & $\begin{array}{l}\text { GaN } \\
(\%)\end{array}$ & $\begin{array}{l}\text { AlN } \\
(\%)\end{array}$ & $\begin{array}{c}\text { Fractional change } \\
\text { in InN (center-edge)/edge }\end{array}$ & $\begin{array}{c}\text { Growth rat } \\
(\mathrm{ML} / \mathrm{s})\end{array}$ \\
\hline R214 & $565 \pm 5$ & 15.7 & 72.8 & 11.5 & 13.0 & 75.4 & 11.6 & 0.2 & 0.411 \\
\hline R213 & $595 \pm 5$ & 8.2 & 79.7 & 12.0 & 4.2 & 83.3 & 12.6 & 1.0 & 0.391 \\
\hline R210 & $615 \pm 5$ & 4.6 & 83.1 & 12.2 & 0.4 & 86.7 & 12.9 & 11.2 & 0.363 \\
\hline R224 & $663 \pm 5$ & 0.0 & 87.2 & 12.8 & 0.0 & 87.0 & 13.0 & & 0.354 \\
\hline \multicolumn{10}{|c|}{ Series B } \\
\hline R181 & $610 \pm 5$ & 9.1 & 85.6 & 5.3 & 4.2 & 90.1 & 5.7 & 1.2 & \\
\hline R192 & $610 \pm 5$ & 7.3 & 79.9 & 12.8 & 3.1 & 83.2 & 13.6 & 1.4 & \\
\hline
\end{tabular}



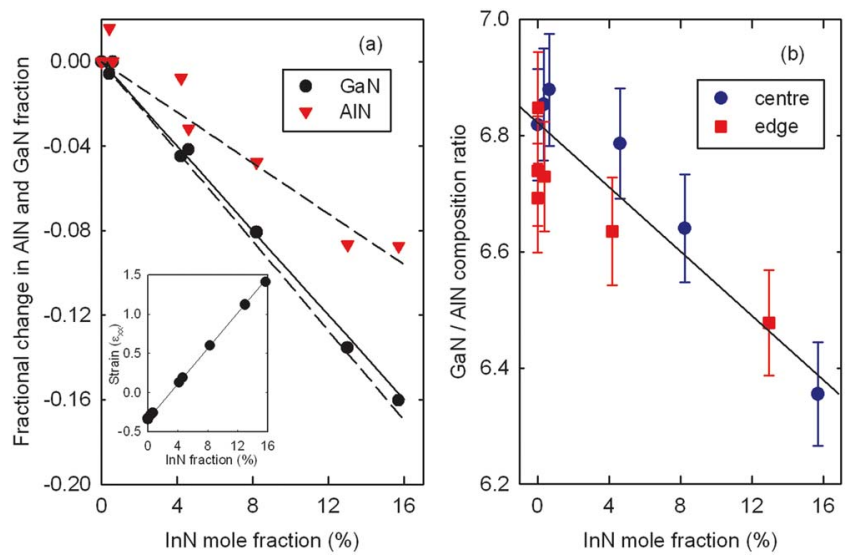

FIG. 3. (Color online) (a) The fractional change in GaN and AIN mole fractions, at both center and edge, as a function of the In mole fraction in series A layers. The lines are described in the text. Inset: the strain computed from lattice mismatch in the AlInGaN as a function of InN fraction. (b) The ratio of the GaN and AlN compositions within series A layers as a function of their InN fraction. The line is a guide for the eye.

Ga desorption probability. Thus, all impinging Ga atoms are also expected to be incorporated within the layer. In contrast, the desorption rate of In is not negligible for temperatures above $550{ }^{\circ} \mathrm{C}$ (Ref. 15) and the sticking coefficient for In will change significantly with temperature. Thus the expectation is that the changes in percentage compositions with series A are due solely to changes in the incorporation of In, with the total amounts of $\mathrm{Al}$ and $\mathrm{Ga}$ remaining fixed. The layer thicknesses would then increase due to the extra In incorporation. As mentioned previously, layer thickness estimates from RBS data are in approximate agreement with this premise. ${ }^{13}$ In the light of these expectations a closer analysis of the composition data for series A will be made.

Figure 3(a) plots the fractional change in GaN and AlN mole fractions, at both center and edge, as a function of the In mole fraction in series A using the WDX data from Table I. The change is measured relative to the point of lowest $\mathrm{InN}$ mole fraction, which is close to zero in both cases. A linear trend is observed for both $\mathrm{Ga}$ and $\mathrm{Al}$, confirming an anticorrelation with the In fraction, as expected from the reasoning above. However the different gradients appear to reveal a stronger anticorrelation for $\mathrm{Ga}$ than for $\mathrm{Al}$. The solid line in Fig. 3(a) shows the fractional change expected for either $\mathrm{GaN}$ or $\mathrm{AlN}$ mole fractions, assuming that all impinging $\mathrm{Al}$ and $\mathrm{Ga}$ are incorporated and the only change is in the amount of In incorporated. This line shows reasonable agreement with the data points for Ga but not for Al. If now it is assumed that the fractional change in $\mathrm{Al}$ is lower than expected by a constant percentage (in this case, reduced by 40\%) the simulated numbers fit both sets of data remarkably well, as shown by the dashed lines in Fig. 3(a). Another way of looking at possible differences in $\mathrm{Al}$ and $\mathrm{Ga}$ incorporations is shown in Fig. 3(b), which plots the ratio of the GaN and AlN mole fractions as a function of the measured $\mathrm{InN}$ for series A. This ratio is observed to decrease monotonically with $\mathrm{InN}$ content even though the ratio between the impinging $\mathrm{Ga}$ and Al flux was kept constant $\left(\Phi_{\mathrm{Ga}} / \Phi_{\mathrm{Al}} \sim 6.5\right)$. The rate of change is slow but is significant when compared to the error bars generated using the fractional uncertainties in the WDX data (0.01). It is not impossible that changes in the flux rates could account for some of the observed trend but a measure of this is provided by the higher growth temperature ( $\mathrm{InN}$ $\approx 0$ ) samples R212 and R224, grown in the middle of the series and some time later, respectively. The measured GaN/ AlN ratios for these samples are closely scattered and distinct from that for the higher InN samples, indicating good control of the $\mathrm{Ga} / \mathrm{Al}$ flux ratio.

Thus, in addition to the main effect of increased InN incorporation at lower growth temperature these data also demonstrate a small but discernible tendency for the $\mathrm{GaN}$ fraction to reduce more rapidly than that of $\mathrm{AlN}$ as the $\mathrm{InN}$ fraction increases. This is surprising in the face of the expected unity sticking coefficients for $\mathrm{Ga}$ and $\mathrm{Al}$ at these temperatures. A possible explanation relates to the strain within the quaternary layers. The lattice mismatch for the measured AlInGaN compositions is plotted in the inset of Fig. 3(a) and is seen to progress linearly from tensile to increasing compressive strain as the $\mathrm{InN}$ fraction increases. This strain will be partially relaxed in some, or all, of our layers but the unrelaxed component could be influencing the incorporation of the different metal elements due to differences in the bond length, which decrease in the order $\mathrm{InN}>\mathrm{GaN}>\mathrm{AlN}{ }^{4}$ For MBE grown GaInNAs Rubini et al. ${ }^{16}$ speculated that strain accompanying the incorporation of extra $\mathrm{N}$ reduces the mobility of the larger In atoms (compared to that of $\mathrm{Ga}$ ) and depresses the In incorporation. Similar reasoning here would imply that the strain resulting from incorporation of extra In depresses the $\mathrm{Ga}$ incorporation relative to that of $\mathrm{Al}$, although it is noted that the Ga evaporation rate is expected to be very small unlike that of the In in the GaInNAs case.

The present results generally agree with those of Monroy et al., ${ }^{4,5}$ where the maximum InN incorporation for a given AlN content was assessed by controlled reduction in the $\mathrm{Ga}$ flux. The maximum incorporation of In was shown to be significantly affected by the substrate temperature and the AlN mole fraction. However, Cremades et al. ${ }^{7}$ reported a different pattern of elemental incorporation in AlInGaN epilayers also grown by PA-MBE. As with our series A samples, the growth temperature was varied in order to obtain different In contents in the samples, with all other parameters kept constant. The observed pattern is that In and Al were incorporated competitively while Ga remained almost constant along the wafer. The AlN fraction was also seen to vary with the growth temperature and island-like features were observed. The series of samples described was grown at higher temperatures than those reported here, which could be the reason for the marked differences in behavior and topography.

In series $\mathrm{B}$ the variation in AlInGaN composition was obtained by maintaining a constant III/V ratio while the $\mathrm{Ga}$ flux was partially replaced by $\mathrm{Al}$ to elucidate the effect of the AlN mole fraction on In incorporation. The composition measured by WDX reveals a uniform $\mathrm{Al}$ incorporation across each piece of the sample, accompanied by small variations in the incorporation of $\mathrm{Ga}$ and In, similar to those observed in the first set of samples (series A). Figure 4 shows the effect of the AlN mole fraction on In incorporation measured in the center and the edge of each sample ( $\mathrm{T}$ edge $>\mathrm{T}$ center). In 


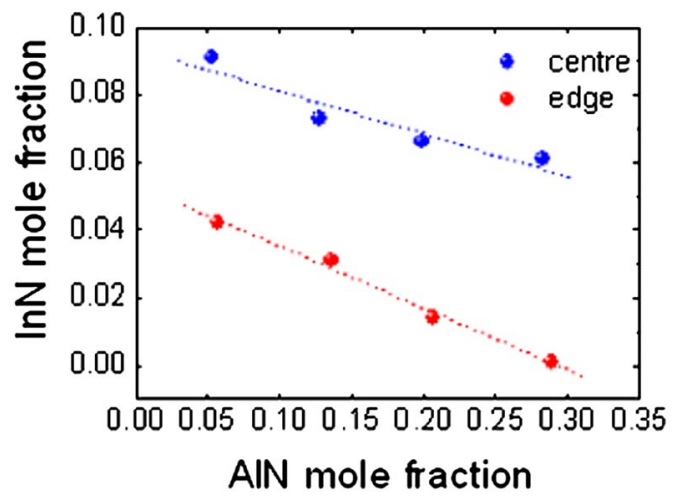

FIG. 4. (Color online) InN mole fraction as a function on AlN mole fraction measured at the center and edge of each sample for series B.

incorporation decreased with the AlN mole fraction despite the fact that both the III/V ratio and the impinging In flux were kept constant. Thus higher $\mathrm{Al}$ fluxes are found to enhance In segregation leading to a reduction in In incorporation. These results are again in close agreement with those of Ref. 4 confirming that the AlN mole fraction limits the amount of In that can be incorporated.

The RT CL spectra from both series showed single emission peaks from the quaternary layers, within a wavelength range from 340 to $430 \mathrm{~nm}$ [spectra from a representative sample were included in Fig. 1(e)], with the peak emission wavelength related directly to the sample composition. The peak emission wavelength is observed to decrease for increasing AlN mole fraction and increase for increasing InN mole fraction. The dependence of the RT peak PL emission wavelength on the composition is presented in Fig. 5(a), which shows data measured from two different spots on each of the "center region" samples from both series along with those from Ref. 17. For comparison the wavelengths corresponding to estimated energy gaps are plotted in Fig. 5(b), although it must be noted that there will be a shift between the emission and excitation energies. ${ }^{5,6}$ These Stokes' shifts have been shown to be large and to have a strong dependence on composition in both InGaN (Ref. 18) and AlInN, ${ }^{19}$ in both cases increasing with the InN content. The band-gap expression for the quaternary $A_{x} B_{y} C_{1-x-y} D$ is taken from

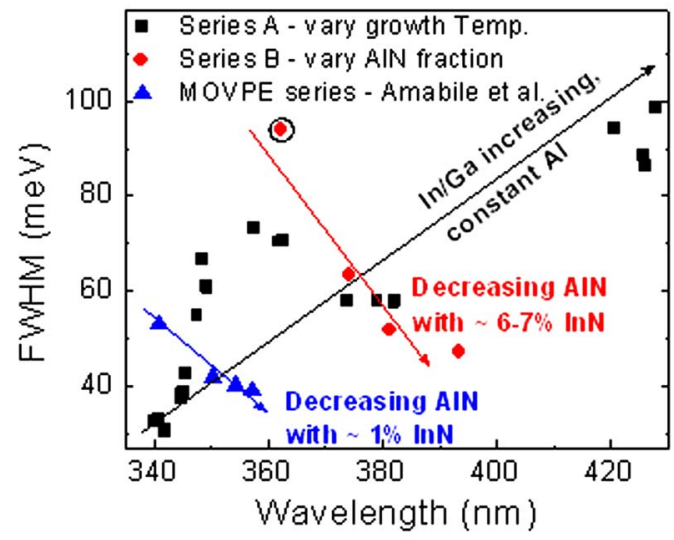

FIG. 6. (Color online) The FWHM of the PL peak plotted against the emission wavelength for the AlInGaN epilayers under study. The circle marks the layer most closely lattice matched to GaN.

Ref. 20, with the three ternary bowing parameters taken to be $1 \mathrm{eV}$ for $\mathrm{AlGaN}, 1.4 \mathrm{eV}$ for InGaN, ${ }^{21,22}$ and $6.0 \mathrm{eV}$ for AlInN. ${ }^{19}$ A higher value of the InGaN bowing parameter (2.4 $\mathrm{eV}$ ) was described in Ref. 5 but, in the present discussion would only result in significant differences for the higher InN fractions. The general trends in the peak emission energies are seen to follow the estimated band-gap energies.

The full width at half maximum (FWHM) of the AlInGaN PL peak was measured for each sample using the $15 \mathrm{~K}$ PL. For some samples where the composition varied along the wafer two points were measured. The linewidth varied from 29 to $100 \mathrm{meV}$ for the wavelength emission ranging from 340 to $430 \mathrm{~nm}$. The variation of the FWHM on the emission wavelength and sample composition is shown in Fig. 6.

The FWHM shows a general increase with increasing emission wavelength for the series with varied growth temperature (series A) as well as with increasing AlN content. An increase with increasing In/Ga ratio (constant $\mathrm{AlN}$ ) is also observed. Earlier AlInGaN epilayers grown by metalorganic vapor phase epitaxy at Sheffield University follow the same tendencies. ${ }^{17}$ The FWHM depends on a complex interplay of many factors, including the effects of electric fields, composition inhomogeneities, and dislocation/defect
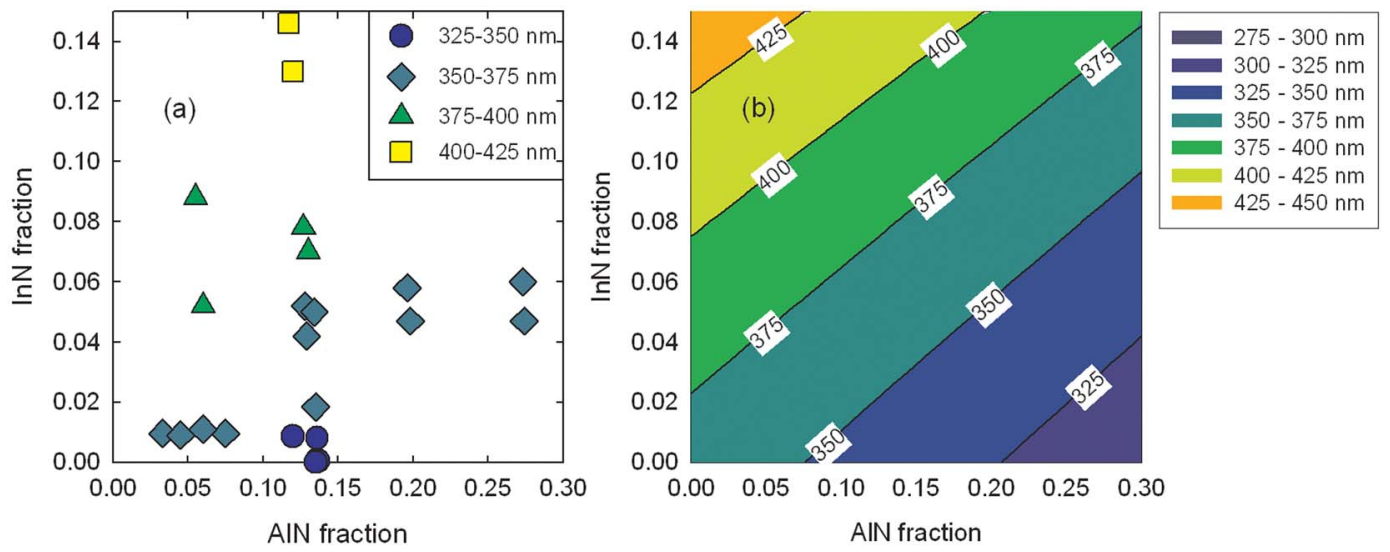

FIG. 5. (Color online) (a) Peak RT PL emission wavelengths and (b) wavelengths corresponding to estimated energy band gaps as a function of AlInGaN composition. 
densities and there is no single trend with emission wavelength. An earlier investigation of AlInGaN epilayers grown by MBE on sapphire with a GaN buffer layer demonstrated a decrease in FWHM and increase in luminescence intensity as the $\mathrm{Al} / \mathrm{In}$ composition ratio brought the layers closer to the lattice-match point. ${ }^{23}$ This was not observed in our series although we have limited data for this region, with sample $\mathrm{R} 188$ being closest to lattice match, $\mathrm{InN} / \mathrm{AlN} \approx 4.6$ (marked by the circle in Fig. 6).

\section{CONCLUSIONS}

Optical and structural characterizations of quaternary AlInGaN compounds grown by PA-MBE have been reported. The incorporation of In is shown to be significantly reduced both by increasing growth temperature as well as by increasing the $\mathrm{Al}$ mole fraction. For AlInGaN layers grown at different temperatures, with other parameters held constant, $\mathrm{x}$-ray elemental mapping demonstrates the anticorrelation in the incorporation of $\mathrm{Ga}$ and $\mathrm{In}$ and, at the same time, a small reduction in the $\mathrm{Ga} / \mathrm{Al}$ composition ratio as the In content increases. The luminescence spectra are dominated by bandedge emission and show a strong dependence on the composition variation. Investigations of correlations between luminescence and composition data are shown to provide important information on the properties of the AlInGaN material.

\section{ACKNOWLEDGMENTS}

The Strathclyde work acknowledges funding from the UK EPSRC through III-N Platform Grants. This work was also partially supported by research grants from the Spanish Ministry of Education (Nos. MAT2004-2875, NAN04/ 09109/C04/2, Consolider-CSD 2006-19, and FPU program); and the Community of Madrid (No. GR/MAT/0042/2004 and S-0505/ESP-0200). RWM thanks Jean Massies (CRHEACNRS) for useful discussions.

${ }^{1}$ M. E. Aumer, S. L. LeBoeuf, F. G. McIntosh, and S. M. Bedair, Appl. Phys. Lett. 75, 3315 (1999).
${ }^{2}$ J. Li, K. B. Nam, K. H. Kim, J. Y. Lin, and H. X. Jiang, Appl. Phys. Lett. 78, 61 (2001).

${ }^{3}$ R. Averbeck and H. Riechert, Phys. Status Solidi A 176, 301 (1999).

${ }^{4}$ E. Monroy, N. Gogneau, D. Jalabert, E. Bellet-Amalric, Y. Hori, F. Enjalbert, L. S. Dang, and B. Daudin, Appl. Phys. Lett. 82, 2242 (2003).

${ }^{5}$ E. Monroy, N. Gogneau, F. Enjalbert, F. Fossard, D. Jalabert, E. BelletAmalric, L. S. Dang, and B. Daudin, J. Appl. Phys. 94, 3121 (2003).

${ }^{6}$ S. Fernández-Garrido, J. Pereiro, F. González-Posada, E. Muñoz, E. Calleja, A. Redondo-Cubero, and R. Gago, J. Appl. Phys. 103, 046104 (2008).

${ }^{7}$ A. Cremades, V. Navarro, J. Piqueras, A. P. Lima, O. Ambacher, and M. Stutzmann, J. Appl. Phys. 90, 4868 (2001).

${ }^{8}$ G. Koblmueller, R. Averbeck, L. Geelhaar, H. Riechert, W. Hösler, and P. Pongratz, J. Appl. Phys. 93, 9591 (2003).

${ }^{9}$ R. W. Martin, P. R. Edwards, K. P. O'Donnell, M. D. Dawson, C. W. Jeon, G. R. Rice, and I. M. Watson, Phys. Status Solidi A 201, 665 (2004).

${ }^{10}$ R. W. Martin, P. R. Edwards, K. P. O'Donnell, E. G. Mackay, and I. M. Watson, Phys. Status Solidi A 192, 117 (2002).

${ }^{11}$ K. Lorenz, N. Franco, E. Alves, I. M. Watson, R. W. Martin, and K. P. O’Donnell, Phys. Rev. Lett. 97, 085501 (2006).

${ }^{12}$ B. Heying, R. Averbeck, L. F. Chen, E. Haus, H. Riechert, and J. S. Speck, J. Appl. Phys. 88, 1855 (2000).

${ }^{13}$ S. Fernández-Garrido, A. Redondo-Cubero, R. Gago, F. Bertram, J. Christen, E. Luna, A. Trampert, J. Pereiro, E. Muñoz, and E. Calleja (to be published).

${ }^{14}$ P. R. Edwards, R. W. Martin, I. M. Watson, C. Liu, R. A. Taylor, J. H. Rice, J. H. Na, J. W. Robinson, and J. D. Smith, Appl. Phys. Lett. 85, 4281 (2004).

${ }^{15}$ C. S. Gallinat, G. Koblmüller, J. S. Brown, and J. S. Speck, J. Appl. Phys. 102, 064907 (2007).

${ }^{16}$ S. Rubini, G. Bais, A. Cristofoli, M. Piccin, R. Duca, C. Nacci, S. Modesti, E. Carlino, F. Martelli, A. Franciosi, G. Bisognin, D. De Salvador, P. Schiavuta, M. Berti, and A. V. Drigo, Appl. Phys. Lett. 88, 141923 (2006).

${ }^{17}$ D. Amabile, R. W. Martin, T. Wang, M. A. Whitehead, and P. J. Parbrook, Phys. Status Solidi C 0, 2478 (2003).

${ }^{18}$ R. W. Martin, P. G. Middleton, K. P. O'Donnell, and W. Van der Stricht, Appl. Phys. Lett. 74, 263 (1999).

${ }^{19}$ K. Wang, R. W. Martin, D. Amabile, P. R. Edwards, S. Hernandez, E. Nogales, K. P. O'Donnell, K. Lorenz, E. Alves, V. Matias, A. Vantomme, D. Wolverson, and I. M. Watson, J. Appl. Phys. 103, 073510 (2008).

${ }^{20}$ M. P. C. M. Krijn, Semicond. Sci. Technol. 6, 27 (1991).

${ }^{21}$ J. Wu, W. Walukiewicz, K. M. Yu, J. W. Ager, E. E. Haller, H. Lu, and W. J. Schaff, Appl. Phys. Lett. 80, 4741 (2002).

${ }^{22}$ K. P. O'Donnell, I. Fernandez-Torrente, P. R. Edwards, and R. W. Martin, J. Cryst. Growth 269, 100 (2004).

${ }^{23}$ B. Z. Wang, X. L. Wang, X. Y. Wang, L. C. Guo, X. H. Wang, H. L. Xiao, and H. X. Liu, J. Phys. D 40, 765 (2007). 